\section{International Scientific Journal Theoretical \& Applied Science}

Umid Qurbanovich Mamayusupov

Senior research scientist

Assistant of the department "Philosophy"

The Nizami Tashkent State Pedagogical University,

Uzbekistan

conference_2012@list.ru

Year: 2015 Issue: 05 Volume: 25

Published: $30.05 .2015 \quad$ http://T-Science.org

SECTION 30. Philosophy.

\title{
PHILOSOPHICAL AND METHODOLOGICAL ANALYSIS OF THE STARTING POINT OF THE PROBLEM OF SCIENTIFIC PREDICTION
}

Abstract: In this article the features of such phenomenon of scientific knowledge as prediction are considered. The relevance of studying this subject is that the future grows from the present and humanity by any means trying to solve the mystery of the future. However, science is interested in scientific prediction, and not, for example, mythological or mystical. Philosophical and methodological analysis of the starting point of the problem of scientific prediction is the main content of this article.

Key words: scientific knowledge, scientific prediction, planning, forecasting, methodology, knowledge.

Language: English

Citation: Mamayusupov UQ (2015) PHILOSOPHICAL AND METHODOLOGICAL ANALYSIS OF THE STARTING POINT OF THE PROBLEM OF SCIENTIFIC PREDICTION. ISJ Theoretical \& Applied Science 05 (25): 30-33.

Soi: http://s-o-i.org/1.1/TAS*05(25)6 Doi: crossef http://dx.doi.org/10.15863/TAS.2015.05.25.6

\section{Introduction}

This article is devoted to a very topical, both in theoretical and in practical terms, scientific topic. The relevance of the article is the fact that the independent Republic of Uzbekistan, entered into the twenty-first century, strongly directed to a progressive future and needs to be scientifically based modern concepts of foresight of the basic parameters of the socio-political, socio-economic, spiritual and cultural development of society.

At the dawn of independence the President of our country Islam Karimov emphasized: "We have just started to build the foundation of our house where we will live in the coming century. It's time to develop and implement long-term, comprehensive programme of development "Uzbekistan in the beginning of the new century". In this programme should reflect the present and future interests of each citizen and each compatriot" [1].

Today, the vision of the future from 20 years ago comes to life in the famous slogan "Uzbekistan is a country with a great future" and that there is a scientific justification.

Philosophical and methodological analysis of the problem of scientific prediction

Every person is not something that every day and almost every minute resort to prediction. Because of this, he is able not only to react to events, but also to control them, which means to be free - build their lives according to their own will and not the will of the circumstances or occasion. About this connection between prediction, control and freedom spoke for Aristotle, when, distinguishing between free man and slave, noted that "the first [being] due to its mental properties are able to foresee, and therefore it is already by nature a creature of the ruling and dominant" [2]. In this context makes sense and catch phrase of Francis Bacon "knowledge is the power". Science allows us to anticipate such events, the knowledge of which cannot be obtained in the framework of everyday cognition, and such objects that cannot be objects of experience, so thanks to it, increasing the power of the person and thus his freedom. However, prediction is quite problematic phenomenon. First, from the point of view of common sense the concept of "prediction" of dubious reputation, which requires a clear statement of criteria that distinguish scientific prediction from astrological forecasts and predictions of clairvoyants. Secondly, questioned repeatedly raised as a logical legitimacy of prediction, and in general the ability to say for sure about the future or unknown. Finally, still not fully clarified the role played by the prediction in the knowledge.

According to specialist of Uzbekistan for research on scientific prediction of Professor K.J.Tulenova: "The modern stage of social development characterized by an extraordinary 
increase of the role of science, which increasingly permeates all aspects of life of people. The level of development of science and of its recommendations depends largely on the development of industry, agriculture, culture, quality of life of people. Scientific knowledge and the level of development of science are now the most valuable national treasure and an important factor of national prestige. Not accidentally, therefore, the interest of scientists to the development of the methodological problems of science is growing every year more and more" [3].

Most of our knowledge is universal and, therefore, the leading nature. In the framework of evolutionary epistemology this is due to the role that knowledge plays in adaptation. The organism can only exist as a relatively stable entity, but this requires the existence of a long-term fixture, which is based on a certain knowledge about the world - the knowledge, having the form of anticipation. Therefore, prediction is an important, a vital form of knowledge. This prediction is not derived from experimental knowledge, on the contrary, the chaos of sense impressions becomes knowledge within a certain prediction - "horizon of expectations". According to V.A.Lektorsky all operations included in cognitive activity ... make sense only in the context of certain assumptions about the real nature of the studied objects" [4]. Therefore, prediction is a fundamental form of knowledge. It may be supported to a greater or lesser degree and can be falsified but not justified, since in its original form not derived by strict logical rules from existing knowledge, and it is a bold imagination. However, prediction can be rational and scientific, which is achieved by awareness of alleged knowledge and critical attitudes towards it. Critical installation causes a person to seek to verify their "horizon of expectations". The inspection is carried out using predictions. Prediction in the universal form - in the form of hypotheses, guesses and general anticipating - must be monitored by prediction in the form of singular existential statements - in the form of predictions. The possibility of prediction it does not require that all processes in the world wore a deterministic nature, but rather is consistent with a reasonable interpretation of indeterminism. Moreover, in the framework of the indeterminism eliminates the contradiction between the various forms of prediction.

Science is constantly experiencing internal, immanent need for a methodological understanding of their own patterns of development, achievements, challenges, problems, difficulties, forms and means of knowledge, to understand the qualitative specifics of various types and levels of scientific and theoretical activity, in particular, scientific prediction, representing the most essential part of spiritual production of person.
One of the central aspects of the development of the methodological problems of modern science is the study of the specificity of scientific prediction as a form of systematic knowledge in the context of the dialectic of subject and object of prediction, the role of the conceptual forms and methods of prediction in obtaining of new knowledge about the world, the role of material and production practices in the formation and development of new knowledge.

The concept of prediction is used most often in the sense of knowledge about the future, and although some authors believed that this was the only possible definition [5], it is clear that it reflects only a special case of prediction. By its very etymology of the term "prediction" indicates obtaining the knowledge to "vision", i.e. before observing, on "the transition of human thought beyond the limits of empirical knowledge in the area of empirically undeveloped" [6]. When people talk about prediction as knowledge of the future, implicitly assume that the past and present known to us. However, in reality, in the space of the future - of the future experience are the objects that already exist or existed. In view of this more correctly, in our view, to define prediction as knowledge about possible objects of future experience, as well as such objects that cannot be included in the experience. Such knowledge can be in the form of calculation on the basis of law and strictly fixed conditions, and in the form of a bold assumption.

Prediction, as a form of development knowledge is a very complex process. It involves educated guesses about the future state of the phenomena of nature and society, or about the phenomena that are unknown at the moment, but identifiable.

Prediction in its content is objectively and is the form of existence of objective truth at some stage, and also participates in the formulation of scientific problems and the ways of its solution. Prediction in complex with different systems of knowledge provides translational motion to scientific knowledge.

If the current position in the process of prediction is perceived as hypothetical knowledge, it allows and even suggests further study of the problem. If the result of scientific research is considered as proven, it will allow us to move from knowledge to action.

It is must reply that prediction is only hypothetical knowledge about the future, and only practice confirms the correctness of this prediction. Undoubtedly, there are a strong correlation predictions and hypotheses; however we can not allow mixing them.

In scientific knowledge to explain the same phenomena, often put forward some hypothetical conditions, which, in turn, may differ in the conceptual framework, either empirically verifiable 
consequences. If a hypothetical situation is different on empirical predictions, then one can solve the experience. Preference is given to the knowledge, a result which is confirmed by the results of observations and experiments. Thus, the proposed prediction is a hypothetical knowledge and its accuracy, faithfulness, truthfulness is proven in practice [7].

Scientific prediction is the actual knowledge, obtained on the basis of knowledge of laws of development of the material world.

Scientific prediction is a critical function of science is understood as knowledge of the future as an advanced reflection of the knowing subject of future states of the object according to the laws of its development. The study of object's states in the past and present allows defining the specific laws of its development and taking into account the sustainability of these laws to determine the next state of the object.

"Formulation of laws, their interpretation, the definition of their manifestations observed in various conditions, etc. is carried out by the theories of science. Since any scientific theory in the process of its development passes through the stage of hypothesis, hypothesis performs the same function, although qualitatively differently is probably not significantly. Explaining the past and the present of the object through the opening of the regularities of its development, theory of science (and hypotheses) explain in a certain extent its future" [8].

In scientific research prediction is a mean of creating hypotheses and the method of their verification. Using the predictions are rejected or approved scientific hypotheses. Scientific prediction is also a mean of testing processes such as description and explanation. "Prediction is the source that powers the future of science. As a transition from abstract knowledge to practice, prediction reveals the importance of scientific hypotheses and theories for practice. The value of scientific theories is determined by the degree of prediction and reliability" [9].

The current situation is such that further progress in all areas of society is impossible without scientific explanation and elaboration on the basis of scientific prediction of the future. The ability to predict the occurrence of the events to give them an explanation to reveal the connection of phenomena, to serve as a practical activity - all this is the need for the existence of science. Since the main purpose of scientific knowledge is to be a conversion tool and the orientation of people in the natural and social environment.

Appearing in every science in different ways prediction is an integral feature of all scientific knowledge and manifests itself in every science differently. Without prediction, and without any other of their functions, any science is simply meaningless. The price of this or that scientific theory is determined by its predictive ability, the truth of the predicted effects, and the application of its results in transformative activities.

Prediction in its content closely with the concepts of forecasting, planning, but they cannot be identified between them.

Undoubtedly, the notion of a scientific prediction is broader than the concepts of forecasting and planning. However, the forecasting, planning encapsulate the specifics of prediction. Forecasts and planning are a mean of mobilizing and organizing for example creative activities of people for the realization of the society goals.

Despite of the similarities prediction, forecast and plan are different from each other. The forecast suggests narrower, specific issues of the future. It is a practical implementation of prediction. The object of scientific prediction includes features mainly qualitative parameters of the future process. Of course, from a scientific prediction cannot be excluded and quantitative analysis. The objects of forecasting and planning increasingly include quantitative certainty, not excluding, of course, qualitative analysis, and, correct to say, proceeding from them.

Planning provides a particular solution to the problems of the future. In the process, it is selected the best option of targeting social object.

Scientific prediction is not intended to show the present and the future in all their individuality and specificity. It sees goal is to make possible the completeness and accuracy to investigate only the most essential and necessary in the chain of events, to find and to determine the laws of their existence, to identify the main problems for the future, to outline the boundaries of the action of forces for their realization.

Prediction is an essential link between the two activities: cognitive and practical. It acts as the most important tool of organization and management of practical activity.

Scientific prediction is directed from the known to the unknown, which raises epistemological uncertainty. In scientific prediction there is a time difference between the assumption of the presence of an existing, but unknown phenomena or the occurrence of new and existing detection or arisen phenomena.

According to K.J.Tulenova, prediction as a procedure, a method of obtaining new knowledge can be classified into different types [10]:

1) Predictable object may refer to the phenomena of nature or of society, or the so-called unique phenomena that can be the object of prediction, geography, cosmology, sociology. For these one, characterized by a minimum frequency, which complicates their prediction and imposes 
special requirements to the prerequisites and the mechanism of their vision;

2) Scientific prediction can be done based on the law, theory or hypothesis, but the main means of scientific prediction is the law. Overall, recurring in the law, acts as a kind of invariant, remaining in a certain class of phenomena with all the changes that are allowed in the system. The general character, expressed in a particular law, it is possible to judge about the specifics of prediction on the basis of the laws of science. So, for example, prediction-based dynamic laws related to such a general nature that is repeated, when the total recurring speaks directly to each individual phenomenon, belonging to the class of phenomena obeying this law. The connection between possibility and reality in these laws is straightforward, which is manifested in the direct determination by one phenomenon to others or their close interdependence, serving, in particular, in the form of functional dependence;

3) Depending on the results of prediction are different qualitative and quantitative assumptions. The nature of the initial information, which is expressed in the laws of science and the claims about specific conditions, prediction in its result can be divided into qualitative and quantitative;

4) In accordance with the nature of the logical apparatus used in scientific prediction differ deductive and inductive prediction. Inside deductive scientific prediction usually distinguish hypotheticaldeductive and empirical-deductive structure of scientific prediction. Hypothetical-deductive structure of scientific prediction is consistent, according to predefined rules of inference, obtaining all the results from the accepted system of hypotheses or laws with their subsequent empirical interpretation. Scientific prediction on empiricaldeductive scheme due to the introduction of as some parcels empirically documentable conditions in connection with a certain law enable us to obtain the assumption of unknown phenomena. Scientific prediction on inductive scheme can be a probabilistic extrapolation of empirically predicted function that satisfactorily expresses a defined sequence properties or relations in a definite space-time interval for similar properties and relationships in a different space-time interval.

\section{Conclusion}

So, the modern concept of scientific prediction is one of the most important concepts of science of the $\mathrm{XXI}^{\text {st }}$ century. This is due to the fact that humanity is at a turning point of its development and how we anticipate the future will depend what it will become in the present.

\section{References:}

1. Karimov IA (1995) Rodina svjashhenna dlja kazhdogo. - Tashkent, Uzbekistan, 1995. pp. 172 .

2. (1983) Aristotel'. Sochinenija v 4-h t., T. 4. Moscow, 1983, 1252 a 30, -pp. 377.

3. Tulenova K (1998) Predvidenie i real'nost'. Tashkent, 1998. -pp.4.

4. Lektorskij VA (1980) Sub`ekt, ob`ekt, poznanie. Moscow, 1980, pp. 206.

5. Hil'kevich AP (1974) Gnoseologicheskaja priroda gipotezy. Minsk, 1974, -pp. 23-27.

6. Zharikov ES (1967) Problema predskazanija v nauke // Logika i metodologija nauki. Moscow, 1967, -pp. 184.
7. Kurnikova EI (1989) Gipoteticheskoe znanie i sposoby ego vyrazhenija $\mathrm{v}$ nauke. Tashkent, 1989. - pp. 18.

8. Hil'kevich AP (1974) Gnoseologicheskaja priroda gipotezy. Minsk, 1974. - pp.25.

9. Matjuhina NA (1974) Gnoseologicheskaja funkcija predvidenija. Moscow, 1974. - pp.338.

10. Tulenova KZ (1998) Predvidenie i real'nost'. Tashkent, 1998. - pp.45-46. 